Communication

\title{
Cyborgs, Robots and Society: Implications for the Future of Society from Human Enhancement with In-The-Body Technologies
}

\author{
Stephen Fox \\ VTT Technical Research Centre of Finland, Vuorimiehentie 3, 02044 Espoo, Finland; stephen.fox@vtt.fi; \\ Tel.: +358-40-747-8801
}

Received: 24 April 2018; Accepted: 18 May 2018; Published: 19 May 2018

\begin{abstract}
Some well-known scientists and technologists have expressed concern that robots may take over the world. More generally, there is concern that robots will take over human jobs and leave billions of people suffering long-term unemployment. Yet, such concerns do not take into account the potential for human beings to enhance their natural capabilities with in-the-body technologies and so become cyborgs with superior capabilities to robots. Types of cyborgs include: human beings with mass produced biomedical implants; human beings with mass imagineered body hacks; and human beings with mass customized insideables. In this paper, human enhancement with in-the-body technologies is analyzed through the theoretical frameworks of mass paradigms, technology domestication, and cultural capital. The implications of the findings of these analyses are related to debates about the future of society. In particular, opportunity versus exploitation, utopia versus dystopia, and emancipation versus extinction. It is explained that that debates about the future of society are flawed if they focus more upon robots than cyborgs. This is because cyborgs can provide more highly advanced embodied cognition, and the number of cyborgs continues to increase as enterprises introduce new in-the-body technologies while individuals seek to increase cultural capital through body projects. Accordingly, debates about the future of society should consider the potential of cyborgs, as well as robots, replacing human beings.
\end{abstract}

Keywords: body hacking; cyborgs; cultural capital; implants; insideables; mass imagineering; robots; sensors; technology domestication; wearables

\section{Introduction}

The "rise of the robots" a prominent topic in debate about the effects of science and technology on society. For example, it has been argued that robots will eventually replace most human workers [1-3]. Moreover, some well-known scientists and technologists have expressed concerns that robots may take over the world $[4,5]$. Yet, such debate does not encompass the potential for human beings to enhance their natural capabilities with in-the-body technologies and so become cyborgs with superior capabilities to robots [6-9]. For example, the acquisition of psychomotor abilities by robots has long been recognized to be a profound challenge [10]. By contrast, human beings have vast repertoires of general psychomotor abilities [11].

As human skin is permeable, the distinction between technology inside and outside of the body can be difficult to delineate precisely. Nonetheless, there are numerous examples of technologies that involve implanting and are beneath the skin. Well-established examples of in-the-body technologies include cochlear implants and heart pacemakers, which are implanted by medical professionals [12]. By contrast, body hackers imagine novel capabilities for themselves; cutting themselves open and implanting their own in-the-body technologies $[13,14]$. As well as professional implanting of medical 
devices for individuals and body hacks by individuals, there are social events for implanting insideables. Unlike wearables, which are electronic devices that people wear as wristbands and other types of apparel outside their bodies, insideables are in-the-body devices. People can have insideables put into their bodies at, so called, implant parties. At these parties, they can share in social interactions similar to those of Botox parties that preceded them $[15,16]$. These three societal trends of human enhancement with in-the-body technologies provide the basis for the descriptive categories of analyses and discussion of implications in this paper. This is appropriate as this paper is concerned with addressing the focus of debate about the future of society, which has hitherto been focused more on robots than on cyborgs.

In this paper, the implications arising from more human beings becoming cyborgs are discussed in relation to debate about the future of society. First, societal trends of human enhancement with implanted technologies are analyzed in terms of three theoretical frameworks: mass paradigms, technology domestication, and cultural capital. Subsequently, implications drawn from analyses are discussed in relation to debates about the future of society concerning opportunity versus exploitation, utopia versus dystopia, and emancipation versus extermination. In conclusion, it is argued that debates about the future of society focused on robots are flawed because of their lack of consideration of cyborgs.

\section{Analyses}

\subsection{Mass Paradigms}

Mass paradigms can be considered as mass production, mass customization, and mass imagineering. These three paradigms offer different levels of authority to individuals. Mass production offers individuals authority over the selection of completed products. Mass customization offers authority at the level of assemblies and sub-assemblies. By contrast, mass imagineering offers individuals authority in engineering what they imagine, including what materials are used and how they will be combined. Consequently, they can be compared and contrasted in terms of the convenience offered by mass production, as, for example, when buying a complete long playing record; the choice offered by mass customization, for example when assembling a personal playlist from music tracks; the creativity offered by mass imagineering, for example when recording at home and sharing one's own music online. These three mass paradigms are related to human enhancement with in-the-body technologies in the following paragraphs.

Mass production is associated with notions of individuals being pacified by cultural content that is provided with such convenience that it requires little, if any, thought [17]. Mass produced culture includes deferential acceptance of medical professionals' advice for standard medical services involving implanting of mass produced in-the-body technologies to restore natural capabilities [12,18]. Beyond the restoration of capabilities, such as hearing and heart functioning, mass produced culture also includes surgical implants to progress towards mass produced exemplars for female and male health and beauty $[19,20]$. This involves many people having surgical implants, even though there is no biomedical need for them [21-24].

By contrast, mass imagineering involves individuals being actively creative. They imagine something, then realize what they imagine with automated engineering. Established participants in mass imagineering are vloggers, self-publishers, and makers. Mass imagineering can involve bricoleurs who make from whatever materials are available to hand; tinkerers who repair/improve what they already have; and creators of assemblages who express themselves with found objects. Some may carry out imagineering to make counter-culture statements. Others may be motivated by a desire to do hands-on work to improve the world. By contrast, others may seek to demonstrate their creativity to attract the commercial interest of established companies involved in mass production. Importantly, they access automated engineers for lighting, sound, manufacturing etc., in the form of sophisticated software and artificial intelligence (AI) that are included in electronic devices, desktop machines, 
and online platforms. Within mass imagineering, individuals have authority throughout production of whatever it is that they imagine $[25,26]$. Mass imagineering includes body hackers who imagine enhanced capabilities for themselves, and put automated engineering devices inside themselves to realize what they imagine. Thus, they engage in a particular type of creative do-it-yourself (DIY). Enhanced capabilities include having automated auditory representations of colors, automated reading of the Earth's seismic movements, and automated notifications every time one faces north in order to become a human compass $[13,14,27,28]$.

Mass customization can provide individuals with more choice than mass production. However, unlike the creative independence of mass imagineering, final authority over product release in mass customization remains with organizations that provide the options that are chosen from [29]. Mass customization is associated with individuals seeking to assemble and promote identities for themselves [30,31], and provides individuals with many options for body modification [32,33]. Within the mass customization of bodies, medical goods can become health and beauty goods [34]. For example, doctors organize Botox parties [35] and Botox is bought online for home parties [36]. Insideables follow from injectables, such as Botox, as technologies that allow mass customization of bodies through individuals selecting from options, such as "getting chipped" with microchips at implant parties $[15,16]$.

\subsection{Technology Domestication}

The transition of technology into everyday use can involve top-down transition across socio-economic modes [37]. First, a mass produced technology can be developed in publicly funded scientific research, next it can be commercialized by the private sector, and then become part of daily life through domestication trails $[15,38]$. DIY is a major trend in technology domestication, which involves people taking care of themselves in domestic settings rather than travelling to consultations with specialists. Such DIY includes, for example, kidney haemodialysis and haemophilia infusions [39,40].

Technology domestication can also involve bottom-up transition across socio-economic modes starting from countercultures participating in mass imagineering [41]. Body hackers apply the counterculture hacker ethic to improve their own bodies with DIY devices [42]. The hacker ethic involves doing hands-on work to improve the world. For example, if all people change themselves by body hacking night vision devices into themselves, there could be no need to consume vast amounts of energy on public lighting [6-9]. In particular, hackers believe that essential lessons can be learned from taking things apart, seeing how they work, and using this knowledge to create new and more interesting things [43]. As with other mass imagineering activities, body hacking can lead to entrepreneurship and commercialization. For example, Web-based enterprises Biohax, Cyborg Nest, and Dangerous Things offer devices, kits, and tools for body hacking [14,27,28]. Thus, body hacking transitions from its counterculture origins towards technology domestication via Web-based sales platforms.

Societal trends of human enhancement with in-the-body technologies can involve technology domestication that leads to some technologies being used at the level of the "technological unconsciousness". In other words, people use technology without conscious consideration of the consequences of doing so [44]. For example, when there is top-down transition across socio-economic modes, the design of implants and implanting procedures during their commercialization can increase ease-of-use, and expand the number of users, to such an extent that some well-established implants might be accepted for use with little questioning by individuals [15]. Nonetheless, a high level of technological consciousness would be required in being a cyborg when there is novelty in what is implanted and how it is implanted. In other words, people are more likely to give conscious consideration to the consequences of doing so [16]. Furthermore, the pragmatics of material interaction require active understanding of how in-the-body technology components should be handled in relation to each other and in relation to the human body [45]. Technological consciousness can be more far 
reaching than mental concentration during selection and use. For example, implants can modify people's perceptions of their own cultural identities to some extent $[46,47]$.

The need for mental concentration, the modification of cultural identity and/or apprehension about implants are not sufficient to prevent the beginning of technology domestication trials. Firstly, the need for improved health can soon motivate people to undertake novel practices, which they would otherwise not consider. For example, DIY faecal transplants at home include passing liquefied excrement provided by a donor down a tube threaded through the nose to the stomach. Unlike the one-off implanting of an in-the-body technology, faecal transplants need to be carried out repeatedly $[48,49]$. Secondly, people can soon get carried away with the hype [50]. The hype associated with the Internet of Things has led to it being referred to as the Internet of Hype [51], and the implanting of in-the-body technologies is being linked to a new slogan with potential for hype, Internet of Bodies [52]. When technology domestication begins based on hype, it is possible that people may be very conscious of their use of technology while not being conscious of why they are starting to use it. This is because they are motivated to begin using a technology due to subconscious Fear of Missing Out (FoMO) and not jumping on whatever is the latest bandwagon of hype [16,50].

\subsection{Cultural Capital}

Cultural capital includes objectified, embodied, and institutionalized cultural capital. Objectified cultural capital is associated with personal belongings that are symbols of cultural capital. By contrast, embodied cultural capital, such as physique and skills, is more integral to a person. Institutionalized cultural capital includes recognition of a person's cultural capital, such as formal qualifications $[53,54]$. Interactions between these categories of cultural capital are illustrated by the example of motorcycle gangs. If an individual has the gang's preferred type of motorcycle and the gang's preferred amount of muscular development, then that individual may be eligible to have and to display the gang's tattoos [55].

From the perspective of top-down mass produced cultural capital, human-enhancement with partially in-the-body technologies can be associated with the objectified cultural capital arising from wearing high-tech consumer devices; the embodied cultural capital of mastering consumer high-tech; and institutionalized cultural capital arising from combining high-tech with consumer brands [56-58]. From the perspective of bottom-up mass imagineering cultural capital, human-enhancement with partially in-the-body technologies can be associated with the objectified cultural capital arising from wearing of do-it-yourself (DIY) microelectronics; the embodied cultural capital of mastering DIY-tech; and institutionalized cultural capital arising from applying DIY-tech within body hacker communities $[13,14,27,28]$.

Although much of cultural capital is determined by background, and top-down mass production, individuals are able to change their cultural capital to some extent. One way of doing this is through body projects in mass imagineering [59-62]. Body projects in becoming a cyborg include examples that illustrate the potential for combination of different categories of cultural capital. For example, Neil Harbisson has an antenna implanted in his head, which is clearly visible to anybody who sees him. This antenna, which could be regarded as a new technology of the self [63] or new technology of optimization [61], transposes color frequencies into sound frequencies. Thus, he realizes what he imagined for himself in becoming a cyborg through the automated engineering of sophisticated software within microelectronic devices [64].

His antenna is a partially in-the-body technology. In particular, the majority of his antenna is a physical object, which is clearly visible as it is several centimeters away from the top of his head. Thus, it can be seen as a source of objectified cultural capital, which is more distinct than sources of objectified cultural capital such as electronic wearables. However, the base of his antenna is implanted and hence embodied. Thus, his antenna has some of characteristics of wearables, which can introduce objectified cultural capital, and some of the characteristics of implants, which can bring embodied cultural capital. Together, they have brought him the institutionalized cultural capital of being the first 
person in the world to be recognized officially by a government as being a cyborg [64]. The potential for institutional recognition specifically among cyborg peers, including those that combine objectified and embodied technologies is facilitated by the Cyborg Foundation, which Harbisson co-founded to support people who want to become cyborgs [65].

Experiencing pain in order to achieve gain from body projects is well established and widely practiced. For example, people follow regimes of extreme physical exercise, such as CrossFit, in order to increase their embodied cultural capital. The extremeness of CrossFit is illustrated by one of its unofficial mascots having been Uncle Rhabdo, which is a symbol for a life-threatening condition brought on by extreme physical exertion called rhabdomyolysis [66]. Human enhancement with in-the-body technologies can also involve experiencing some pain in order to achieve some gain. However, unlike repetitive activities such as CrossFit, the pain may only be one-off during implanting surgery $[13,14,27,28]$.

\section{Implications}

\subsection{Opportunity Versus Exploitation}

Human enhancement with in-the-body technologies introduces new cases into the debate about whether individuals are subject to increased opportunity or increased exploitation because of new technology. The body hacking suppliers Biohax, Cyborg Nest, and Dangerous Things are examples of new opportunities for Web-based enterprises to come from mass imagineering communities. By contrast, body hacking could be argued to be a new example of exploitation where workers are paid less than the value of what they produce. In particular, body hackers act like pioneering scientists from previous centuries by undertaking DIY experiments without any expectation of financial rewards [67]. Meanwhile, such experiments are of benefit for established technology companies who can learn from the self-experiments of body hackers without incurring any costs.

Also, human enhancement with in-the-body technology introduces new cases into the debate about digital exploitation [68]. In particular, it is argued that individuals will be exploited without their realizing through digital infrastructures that draw individuals into unknowingly providing personal data $[69,70]$. However, as with other applications of digital technology, different mass paradigms bring different possibilities for data exploitation and data privacy. Mass production is associated with concerns about the potential for technological unconsciousness in panoptic "Big Brother Is Watching You" through "dataveillance" [71-73]. This is possible via remote monitoring of surgical implants over long-range, high-bandwidth wireless links [74,75]. Rather than "Big Brother Is Watching You dataveillance", mass imagineering can enable technological conscious synoptic "Little Brother Is Watching Back" [76]: for example, by implanting cameras into the back of the head [77]. In between mass production's Big Brother panoptics and mass imagineering's Little Brother synoptics are mass customization's surveillance enticements to encourage individuals to participate knowingly with digital infrastructures set up by organizations [78]. For example, by "getting chipped" at offices parties arranged by employers [79].

Thus, human enhancement with in-the-body technologies introduces new potential for both individual opportunity and individual exploitation. As before, taking opportunities and avoiding exploitation involves more bottom-up imagination and technological consciousness than is needed to gain standardized cultural capital through passive consumption of mass-produced offerings.

\subsection{Utopia Versus Dystopia}

When debate concerning the consequences of new technologies is about society, argument can be framed in terms of utopia versus dystopia. Utopian discourse includes the rejection of the existing society and the proposition that another society is possible and desirable. Then, utopian practices seek to create at least some of the features of this utopian discourse in the hope of them spreading throughout society [80]. Techno-utopia propositions include arguments that technological advances should bring 
about utopias where human beings transcend the constraints of biology, and become transhuman or even posthuman [81]. However, this techno-utopia is regarded by some as a very dangerous idea that will actually lead to a techno-dystopia of enhanced "haves" and unenhanced "have-nots" living in societies that are more polarized than before widespread human enhancement [82-84].

Such conceptualizations of techno-dystopias do not take into account technology domestication, which involve thoughtful trials and modifications of technologies to suit the requirements and preferences of individuals. Technology domestication can be informed by the early users of technologies who may have begun their use due to hype, but who go on to widely share their experiences and advice for adaptations via the Internet [36,38]. Rather, they are based on technology determinism, which involves the assumption that technology is an irresistible force in determining social change [85]. In particular, they do not take into account the increase in DIY at home that is driven both by top-down mass production and by bottom-up mass imagineering. Moreover, in between mass production and mass imagineering, the mass customization of bodies is very well established and already encompasses insideables. Thus, deterministic prognoses of techno-dystopias based on injustices in the distribution of human enhancement do not take into account cultures of mass paradigms. For example, cyborg conspicuous consumption can include in-the-body technologies that are hand-made by professional craftsperson. At the same time, cyborg DIY prosumption can include homemade in-the-body technologies, which can be undertaken without previous relevant experience and with a few low cost technological resources $[13,14,27,28]$.

Furthermore, deterministic conceptualizations of techno-dystopias do not take into account the subtleties of cultural capital, which affect the direction and speed of social changes [86,87]. For example, cyborgs with partially in-the-body technology could be viewed as being uncannily not quite human, and so referred to by synonyms for uncanniness such as creepy, freaky, and strange. By contrast, cyborgs with fully in-the-body technologies might be viewed as being much the same as before becoming cyborgs $[88,89]$. For example, there are fully in-the-body implants that can link the human brain and human nervous system to computers. These include already established active neuro-stimulator devices to reduce chronic musculoskeletal pain [90] and currently experimental neuroprosthetics that can improve human memory function [91]. Thus, rather than in-the-body technologies bringing rapid polarizing change to society by irresistible waves of technological determinism, myriad framings and reframings of cultural capital involve myriad trials and retrials of technology domestication as people think and rethink their relationship between the self and others [92].

\subsection{Emancipation Versus Extermination}

When debate concerning the consequences of new technologies is about all of humanity, it can be framed in terms of new technology bringing the emancipation or the extermination of human beings. Interestingly, arguments for these two alternative outcomes can both include assertions that robots will determine the fate of humanity. Those who foresee human emancipation envisage that robots will undertake all work and pay for human entertainment. Conversely, those who foresee human extermination envisage that robots will consume all available resources-including human beings. Such debate about the future of humanity takes opportunity versus exploitation and utopia versus dystopia to the conclusions that humanity will live happily in a utopian society of opportunity, for example, versus humanity will die out in a dystopia society of exploitation [1-5,93-95]. For example, arguments for human emancipation from work by robots that pay for human entertainment include the work of robots being taxed to pay for universal basic human income [96]. Meanwhile, arguments for human extermination by robots include propositions that robots can pose existential threats to human beings even when robots are programmed to pursue seemingly harmless goals. One such scenario being that an advanced robot programmed to manufacture paperclips would optimized this goal by turning all matter, including human beings, into either paperclips or machines that manufacture paperclips [97]. 
There is little mediation of such extreme scenarios by means of consideration of human enhancement with in-the-body technologies. Firstly, there is little consideration that human enhancement is a more efficient means of achieving versatile embodied intelligence than building robots. This is because psychomotor skills that are natural to human beings require enormous computational resources and complex morphological flexibility. Typically, while it is possible to make computers exhibit better than human performance in playing chess or Go, it is much more difficult (or perhaps impossible) to give them human skills simultaneously combining physical agility, sensory perception, and cognitive processing [10,98-100]. Thus, mass production, mass customization, and mass imagineering involving in-the-body technologies to enhance human beings is a much more efficient use of resources than consuming far more materials and energy in efforts to build robots that can go beyond the natural levels of human embodied intelligence.

Indeed, debate about human emancipation versus human extinction does not take into consideration that mass human enhancement is entirely within the scope of existing mass paradigms. For example, in addition to the millions of body projects undertaken to meet biomedical needs, there are millions of body enhancing projects undertaken to improve cultural capital across mass paradigms. Moreover, these body projects involve the notion of gain depending upon pain i.e., no pain no gain. Thus, body projects often involve repeated pain and discomfort, which can be much more than that of implanting in-the-body technologies. For example, people try continually to increase their cultural capital through activities including repeated extreme physical training and repeated plastic surgery $[22,23,66]$. For example, brain implants can be used to meet biomedical needs, but alternatively can be used solely for capacity enhancing purposes. In both cases, direct connections with the brain open up the possibility for individuals to communicate with each other, control machines with their thoughts, and/or be connected to the Internet constantly. Indeed, it has been argued that non-medical implants will become mainstream once the benefits they provide outstrip those of wearables; and it is only a matter of time until non-disabled people begin to use brain implants to improve upon their natural capabilities to suit their own particular requirements [101]. A notable case of brain implant innovation is that of BrainGate, which consists of a sensor implanted in the brain and an external decoder device, which can be connected to different types of prosthetics or other external objects. The sensor is in the form of a multi-electrode array, which consists of 100 hair-thin electrodes that sense the electromagnetic signature of neurons firing in specific areas of the brain, for example, the area that controls arm movement. The sensor translates that activity into electrically charged signals. Then, these are sent to an external device and decoded in software. The decoder connects to an external device, such as a computer cursor, a robotic arm, or a light vehicle, and can use the brain signals to control it [102]. Thus, BrainGate allows a person to manipulate objects in the world using only the mind. Such brain implants can restore or enhance human functioning and so reduce the human need for robots in the future. Hence, those who consider the future of humanity in terms of either emancipation or extinction because of robots, fail to recognize that human enhancement as cyborgs with in-the-body technologies is an increasingly widespread practice that reduces the comparative advantages of robots and human needs for robots.

\section{Conclusions}

Cyborgs are increasing through the dynamics of mass paradigms, technology domestication, and cultural capital. More enterprises are introducing in-the-body technologies across mass paradigms, and more in-the-body technologies are becoming commonplace through technology domestication. At the same time, more individuals are seeking to increase cultural capital through body projects. Accordingly, debates about the future of society that are focused on robots are flawed, because they fail to consider the increasing numbers of cyborgs who will have capabilities superior to robots. Accordingly, debates about the future of society should consider the potential of cyborgs, as well as robots, replacing human beings. In particular, the potential cyborgs should be considered in debates about the future of society that encompass arguments about whether the replacement of human beings will lead to opportunity 
or exploitation, utopia or dystopia, and emancipation or extermination. Overall, the objective of this paper is to introduce a more balanced perspective into the debate about the future of society that is currently skewed in its focus on robots.

Funding: This research received no external funding.

Conflicts of Interest: The author declares no conflict of interest.

\section{References}

1. Brynjolfsson, E.; McAfee, A. The Second Machine Age: Work, Progress, and Prosperity in Time of Brilliant Technologies; W.W. Norton \& Company, Inc.: New York, NY, USA, 2014.

2. Corbyn, Z. Robots are leaving the factory floor and heading for your desk-and your job. The Guardian, 9 February 2015.

3. Ford, M. The Rise of the Robots: Technology and the Threat of Mass Unemployment; One World Publications: London, UK, 2015.

4. Griffin, A. Stephen Hawking, Elon Musk and others call for research to avoid dangers of artificial intelligence. The Independent, 12 January 2015.

5. Holley, P. Bill Gates on dangers of artificial intelligence: 'I don't understand why some people are not concerned'. The Washington Post, 29 January 2015.

6. Carvalko, J. The Techno-Human Shell: A Jump in the Evolutionary Gap; Sunbury Press: Mechanicsburg, PA, USA, 2012.

7. Clynes, M.E.; Kline, N.S. Cyborgs and space. Astronautics 1960, 30, 26-27/74-76.

8. Halacy, D.S. Cyborg: Evolution of the Superman; Harper and Row Publishers: New York, NY, USA, 1965.

9. Haraway, D. A Cyborg Manifesto: Science, Technology, and Socialist-Feminism in the Late Twentieth Century, in Simians, Cyborgs and Women: The Reinvention of Nature; Routledge: New York, NY, USA, 1994; pp. 150-182.

10. Moravec, H. Mind Children; Harvard University Press: Cambridge, MA, USA, 1988.

11. Pfeifer, R.; Bongard, J. How the Body Shapes the Way We Think: A New View of Intelligence; MIT Press: Cambridge, MA, USA, 2006.

12. Oudshoorn, N. Sustaining cyborgs: Sensing and tuning agencies of pacemakers and implantable cardioverter defibrillators. Soc. Stud. Sci. 2015, 45, 56-76. [CrossRef] [PubMed]

13. Borland, J. Transcending the Human, DIY Style. Wired Magazine, 30 December 2010.

14. Wainwright, O. Body-hackers: The people who turn themselves into cyborgs. The Guardian, 1 August 2015.

15. Cook, P.S.; Dwyer, A. No longer raising eyebrows: The contexts and domestication of Botox as a mundane medical and cultural artefact. J. Consum. Cult. 2017, 17, 887-909. [CrossRef]

16. Eveleth, R. Why did I implant a chip in my hand? My so-called cyborg life. Popular Science, 24 May 2016.

17. Slater, D. Consumer Culture and Modernity; Polity Press: Cambridge, UK, 1997.

18. Kennelly, C.; Bowling, A. Suffering in deference: A focus group study of older cardiac patients' preferences for treatment and perceptions of risk. Qual. Saf. Health Care 2001, 10, 23-28. [CrossRef]

19. Blum, V.L. Objects of love: I Want a Famous Face and the illusions of star culture. Configurations 2007, 15, 33-53. [CrossRef]

20. Volonté, P. The thin ideal and the practice of fashion. J. Consum. Cult. 2017. [CrossRef]

21. Akass, K.; McCabe, J. A perfect lie: Visual (dis)pleasures and policing femininity in Nip/Tuck. In Makeover Television: Realities Remodelled; Heller, D., Ed.; I.B. Tauris: London, UK, 2007; pp. 119-132.

22. Holliday, R.; Cairnie, A. Man made plastic: Investigating men's consumption of aesthetic surgery. J. Consum. Cult. 2007, 7, 57-78. [CrossRef]

23. Morgan, K.P. Women and the knife: Cosmetic surgery and the colonization of women's bodies. Hypatia 1991, 6, 25-53. [CrossRef]

24. Polonijo, A.N.; Carpiano, R.M. Representations of cosmetic surgery and emotional health in women's magazines in Canada. Women's Health Issues 2008, 18, 463-470. [CrossRef] [PubMed]

25. Fox, S. Mass imagineering: Combining human imagination and automated engineering from early education to digital afterlife. Technol. Soc. 2017, 51, 163-171. [CrossRef]

26. Ritzer, G. Prosumer capitalism. Sociol. Q. 2007, 56, 413-445. [CrossRef] 
27. Popescu, A. This \$425 DIY Implant Will Make You a Cyborg: Cyborg Nest manufactures DIY kits meant to bring transhumanism to the masses. Bloomberg, 16 February 2017.

28. Popper, B. Cyborg America: Inside the strange new world of basement body hackers. Verge Magazine, 8 August 2012.

29. Agrawal, M.; Kumaresh, T.V.; Mercer, G.A. The false promise of mass Customization. McKinsey Q. 2002, 38, 62-71.

30. Featherstone, M. Consumer Culture and Postmodernism; Sage: London, UK, 1991.

31. Hearn, A. Meat, mask, burden: Probing the contours of the branded self. J. Consum. Cult. 2008, 8, $197-217$. [CrossRef]

32. Davis, K. Dubious Equalities and Embodied Differences: Cultural Studies on Cosmetic Surgery; Rowman \& Littlefield: Lanham, MD, USA, 2003.

33. Gimlin, D. Body Work: Beauty and Self-Image in American Culture; University of California Press: Berkeley, CA, USA, 2001.

34. Hardey, M. Consuming professions: User-review websites and health services. J. Consum. Cult. 2010, 10, 129-149. [CrossRef]

35. Clough, S. Oklahoma doctors' Botox parties draw new patients. Journal Record, 7 November 2007, p. 1.

36. Smit, M. Taming monsters: The cultural domestication of new technologies. Technol. Soc. 2006, 28, 489-504. [CrossRef]

37. Berkowitz, D. Botox Nation: Changing the Face of America; NYU Press: New York, NY, USA, 2017.

38. Lehtonen, T.-K. The domestication of new technologies as a set of trials. J. Consum. Cult. 2003, 3, 363-385. [CrossRef]

39. Tennankore, K.K.; Kim, S.J.; Baer, H.J.; Chan, C.T. Survival and hospitalization for intensive home hemodialysis compared with kidney transplantation. J. Am. Soc. Nephrol. 2014, 25, 2113-2120. [CrossRef] [PubMed]

40. Young, G.; Escobar, M.A.; Pipe, S.W.; Cooper, D.L. Safety and efficacy of recombinant activated coagulation Factor VII in congenital hemophilia with inhibitors in the home treatment setting: A review of clinical studies and registries. Am. J. Hematol. 2017. [CrossRef] [PubMed]

41. Arvidsson, A. From counterculture to consumer culture: Vespa and the Italian youth market, 1958-1978. J. Consum. Cult. 2001, 1, 47-71. [CrossRef]

42. Coleman, E.G.; Golub, A. Hacker practice: Moral genres and the cultural articulation of liberalism. Anthropol. Theory 2008, 8, 255-277. [CrossRef]

43. Levy, S. Hackers: Heroes of the Computer Revolution; Anchor Press/Doubleday: Garden City, NY, USA, 1984; Volume 14.

44. Thrift, N. Remembering the technological unconscious by foregrounding knowledges of position. Environ. Plan. D Soc. Space 2004, 22, 175-190. [CrossRef]

45. Dant, T. The Pragmatics of Material Interaction. J. Consum. Cult. 2008, 8, 11-33. [CrossRef]

46. Helman, C.G. The body image in health and disease: Exploring patients' maps of body and self. Patient Educ. Couns. 1995, 26, 169-175. [CrossRef]

47. Wald, R.L.; Knutson, J.F. Deaf cultural identity of adolescents with and without cochlear implants. Ann. Otol. Rhinol. Laryngol. 2000, 109, 87-89. [CrossRef]

48. Floch, M.H. The power of poop: Probiotics and fecal microbial transplant. J. Clin. Gastroenterol. 2012, 46, 625-626. [CrossRef] [PubMed]

49. Silverman, M.S.; Davis, I.; Pillai, D.R. Success of self-administered home fecal transplantation for chronic clostridium difficile infection. Clin. Gastroenterol. Hepatol. 2010, 8, 471-473. [CrossRef] [PubMed]

50. Nadeau, R.; Cloutier, E.; Guay, J.-H. New Evidence about the Existence of a Bandwagon Effect in the Opinion Formation Process. Int. Political Sci. Rev. 1993, 14, 203-213. [CrossRef]

51. The Economist The "internet of things": The internet of hype. The Economist, 9 December 2010.

52. Neal, M. The Internet of Bodies Is Coming, and You Could Get Hacked. Motherboard, 13 March 2014.

53. Bourdieu, P. Distinction: A Social Critique of the Judgement of Taste; Harvard University Press: Cambridge, MA, USA, 1984.

54. Bourdieu, P. Social space and symbolic power. Sociol. Theory 1989, 7, 14-25. [CrossRef]

55. Halnon, K.B.; Cohen, S. Muscles, motorcycles and tattoos: Gentrification in a new frontier. J. Consum. Cult. 2006, 6, 33-56. [CrossRef] 
56. Kapitzke, C. Information technology as cultural capital: Shifting the boundaries of power. Educ. Inf. Technol. 2000, 5, 49-62. [CrossRef]

57. Lado, N.; Cesaroni, F.; Maydeu-Olivares, A.; Ho, H.C. Co-branding strategies of high-tech products and luxury brands: A cross-cultural perspective. In Let's Get Engaged! Crossing the Threshold of Marketing's Engagement Era; Springer: Cham, Switzerland, 2016; pp. 401-402.

58. Tamminen, S.; Holmgren, E. The anthropology of wearables: The self, the social, and the autobiographical. Proc. Ethnogr. Praxis Ind. Conf. 2016, 1, 154-174. [CrossRef]

59. Foucault, M. Technologies of the Self: A Seminar with Michel Foucault; Martin, L.H., Gutman, H., Hutton, P.H., Eds.; University of Massachusetts Press: Amherst, MA, USA, 1988.

60. Gill, R.; Henwood, K.; McLean, C. Body projects and the regulation of normative masculinity. Body Soc. 2005, 11, 37-62. [CrossRef]

61. Rose, N. The Politics of Life Itself: Biomedicine, Power, and Subjectivity in the Twenty-First Century; Princeton University Press: New Brunswick, NJ, USA, 2007.

62. Shilling, C. The Body and Social Theory; Sage: London, UK, 2012.

63. Foucault, M. Governmentality, translated by Rosi Braidotti and revised by Colin Gordon. In The Foucault Effect: Studies in Governmentality; Burchell, G., Gordon, C., Miller, P., Eds.; University of Chicago Press: Chicago, IL, USA, 1991; pp. 87-104.

64. Jeffries, S. Neil Harbisson, the world's first cyborg artist. The Guardian, 5 May 2014.

65. Solon, O. The Cyborg Foundation: We urge you to become part-machine. Wired, 30 October 2013.

66. Powers, D.; Greenwell, D.M. Branded fitness: Exercise and promotional culture. J. Consum. Cult. 2017, 17, 523-541. [CrossRef]

67. Altman, L.K. Who Goes First? The Story of Self-Experimentation in Medicine; University of California Press: Berkeley, CA, USA, 1998.

68. Liao, Y.; Leeson, M.S.; Cai, Q.; Ai, Q.; Liu, Q. Mutual-Information-Based Incremental Relaying Communications for Wireless Biomedical Implant Systems. Sensors 2018, 18, 515. [CrossRef] [PubMed]

69. Ritzer, G. Prosumption: Evolution, revolution, or eternal return of the same? J. Consum. Cult. 2014, 14, 3-25. [CrossRef]

70. Zwick, D. Defending the right lines of division: Ritzer's prosumer capitalism in the age of commercial customer surveillance and big data. Sociol. Q. 2015, 56, 484-498. [CrossRef]

71. Clarke, R.A. Information technology and dataveillance. Commun. ACM 1988, 31, 498-512. [CrossRef]

72. Elmer, G. A diagram of panoptic surveillance. New Media Soc. 2003, 5, 231-247. [CrossRef]

73. Orwell, G. Nineteen Eighty-Four: A Novel; Secker \& Warburg: London, UK, 1949.

74. Halperin, D.; Heydt-Benjamin, T.S.; Fu, K.; Kohno, T.; Maisel, W.H. Security and privacy for implantable medical devices. IEEE Pervasive Comput. 2008, 7, 30-39. [CrossRef]

75. Rushanan, M.; Rubin, A.D.; Kune, D.F.; Swanson, C.M. Security and privacy in implantable medical devices and body area networks. In Proceedings of the IEEE Symposium on Security and Privacy (SP), San Jose, CA, USA, 18-21 May 2014; pp. 524-539.

76. Andén-Papadopoulos, K. Citizen camera-witnessing: Embodied political dissent in the age of 'mediated mass self-communication'. New Media Soc. 2014, 16, 753-769. [CrossRef]

77. Boyle, S. Professor Surgically Installs Camera in Head, Starts Tracking the World Behind Him. Popular Science, 3 December 2010.

78. Whitaker, R. The End of Privacy: How Total Surveillance Is Becoming a Reality; New Press: New York, NY, USA, 1999.

79. Paquette, D. Some feared hackers and the devil. Others got microchipped. The Washington Post, 1 August 2017.

80. Bossy, S. The utopias of political consumerism: The search of alternatives to mass consumption. J. Consum. Cult. 2014, 14, 179-198. [CrossRef]

81. Kurzweil, R. The Singularity Is Near: When Humans Transcend Biology; Viking: New York, NY, USA, 2005.

82. Annas, G.; Andrews, L.; Isasi, R. Protecting the endangered human: Toward an international treaty prohibiting cloning and inheritable alterations. Am. J. Law Med. 2002, 28, 151-178. [PubMed]

83. Fukuyama, F. The world's most dangerous ideas: Transhumanism. Foreign Policy 2004, 144, 42-43. [CrossRef]

84. Hansell, G.; Grassie, W. H+/-: Transhumanism and Its Critics; Metanexus Institute: Philadelphia, PA, USA, 2011.

85. Marx, L.; Smith, M.R. Does Technology Drive History? The Dilemma of Technological Determinism; MIT Press: Cambridge, MA, USA, 1994. 
86. Annavarapu, S. Consuming wellness, producing difference: The case of a wellness center in India. J. Consum. Cult. 2016. [CrossRef]

87. Hazır, I.K. Wearing class: A study on clothes, bodies and emotions in Turkey. J. Consum. Cult. 2016. [CrossRef]

88. Layne, L.L. Creepy,' 'freaky,'and 'strange': How the 'uncanny'can illuminate the experience of single mothers by choice and lesbian couples who buy 'dad. J. Consum. Cult. 2013, 13, 140-159. [CrossRef]

89. Royle, N. The Uncanny; Manchester University Press: Manchester, UK, 2003.

90. Liem, L.; Russo, M.; Huygen, F.J.; Buyten, V.; Smet, I.; Verrills, P.; Cousins, M.; Brooker, C.; Levy, R.; Deer, T.; Kramer, J. One-year outcomes of spinal cord stimulation of the dorsal root ganglion in the treatment of chronic neuropathic pain. Neuromodulation Technol. Neural Interface 2015, 18, 41-49. [CrossRef] [PubMed]

91. Hampson, R.E.; Song, D.; Robinson, B.S.; Fetterhoff, D.; Dakos, A.S.; Roeder, B.M.; She, X.; Wicks, R.T.; Witcher, M.R.; Couture, D.E. Developing a hippocampal neural prosthetic to facilitate human memory encoding and recall. J. Neural Eng. 2018, 15, 036014. [CrossRef] [PubMed]

92. Joy, A.; Sherry, J., Jr.; Troilo, G.; Deschenes, J. Re-thinking the relationship between self and other: Levinas and narratives of beautifying the body. J. Consum. Cult. 2010, 10, 333-361. [CrossRef]

93. Russell, S.; Dewey, D.; Tegmark, M. Research Priorities for Robust and Beneficial Artificial Intelligence. AI Mag. 2015, 36, 105-114. [CrossRef]

94. Sparkes, M. Top scientists call for caution over artificial intelligence. The Telegraph, 13 January 2015.

95. Vinge, V. The Coming Technological Singularity: How to Survive in the Post-Human Era. In Vision-21: Interdisciplinary Science and Engineering in the Era of Cyberspace; Landis, G.A., Ed.; NASA Publication: Washington, DC, USA, 1993; pp. 11-22.

96. Abbott, R.; Bogenschneider, B. Should Robots Pay Taxes? Tax Policy in the Age of Automation (13 March 2017). Harvard Law \& Policy Review. 2018, Volume 12. Available online: https:/ / ssrn.com/abstract=2932483 (accessed on 9 May 2018).

97. Bostrom, N. Ethical issues in advanced artificial intelligence. In Cognitive, Emotive and Ethical Aspects of Decision Making in Humans and in Artificial Intelligence; Smit, I., Lasker, G.E., Eds.; International Institute for Advanced Studies in Systems Research and Cybernetics: Windsor, ON, Canada, 2003; Volume 2, pp. $12-17$.

98. Brooks, R.A. Elephants don't play chess. Robot. Auton. Syst. 1990, 6, 3-15. [CrossRef]

99. Qiu, J. Research and development of artificial intelligence in China. Natl. Sci. Rev. 2016, 3, 538-541. [CrossRef]

100. Rotenberg, V.S. Moravec's paradox: Consideration in the context of two brain hemisphere functions. Act. Nerv. Super. 2013, 55, 108-111. [CrossRef]

101. Ochsner, B.; Spöhrer, M.; Stock, R. Human, non-human, and beyond: Cochlear implants in socio-technological environments. NanoEthics 2015, 9, 237-250. [CrossRef]

102. Willett, F.R.; Pandarinath, C.; Jarosiewicz, B.; Murphy, B.A.; Memberg, W.D.; Blabe, C.H.; Saab, J.; Walter, B.L.; Sweet, J.A.; Miller, J.P. Feedback control policies employed by people using intracortical brain-computer interfaces. J. Neural Eng. 2016, 14, 016001. [CrossRef] [PubMed] 